\title{
Effect of Combining Clinical Teaching Tools on Clinical Judgment Skills of Undergraduate Nursing Students in Kenya
}

\author{
*Corresponding Author \\ Wachira Serah \\ Article History \\ Received: 21.10 .2020 \\ Accepted: 05.11.2020 \\ Published: 07.11.2020
}

Wachira Serah ${ }^{1 *}$, Karani Anna ${ }^{2}$, Kimani Samuel ${ }^{2}$, Mageto Irene $^{2}$

${ }^{\mathrm{T}}$ Department of Nursing, Daystar University Nairobi

${ }^{2}$ Department of Nursing University of Nairobi

\begin{abstract}
The need to improve clinical judgment competencies during training has been necessitated by the demand for the preparation of new nurse graduates to face an arena characterized by nurse shortage and acutely ill yet more informed clients. In Kenya, the nursing process has been the primary tool to help student nurses develop clinical judgment skills. However, local studies show glaring clinical judgment gaps among new nurse graduates that threaten safe patient care. There is, therefore, a need to examine how a combination of more evidence-based tools can enhance clinical judgment development to improve training outcomes. A quasi-experiment was used to conduct the study. This involved a case study based on pre-test and post-test used to evaluate clinical judgment development in both groups. Furthermore, the groups were used to evaluate the effect of combining two clinical teaching tools on clinical judgment competency scores. The study involved 82 undergraduate nursing students. The respondents had a mean age of $21.50 \pm 1.34$ years for the Intervention group and $21.59 \pm 1.43$ years for the control group. $34.15 \%$ of the respondents were male, while $65.85 \%$ were female. The outcomes of the pre-test and post-test scores across the year of study depict a significant improvement with below expectation $<49 \%$ reducing from $39.02 \%$ to $28.99 \%$ among second-year student and $28.05 \%$ to $7.25 \%$ among the third-year students. Scores of relationships between improvement of CJ Skills Scores across Gender, Cluster, and Cohort proved to be insignificant with cohort only significant $(P<0.035)$. There was a significant difference in the scores for Control Post-Test-Control Pre-test and $(\mathrm{M}=2.947, \mathrm{SD}=15.174)$ and Intervention post-testIntervention Pre-test $(\mathrm{M}=14.100, \mathrm{SD}=14.398)$ conditions; $t(38)=-6.116, \mathrm{p}=0.0001$." The findings showed a significant effect in combining clinical teaching tools on clinical judgment competency scores compared to the nursing process alone $(\mathrm{p}=0.0000)$. The study findings imply the need to review clinical nurse training to incorporate more evidencebased strategies. However, the study recommends similar research to be carried out in multiple clinical sites to enhance the evidence's strength and the generalizability of the results and outcomes.
\end{abstract}

Keywords: Nursing, competencies, nursing students, clinical judgment, Kenya.

\section{INTRODUCTION}

As Simmons [1] described, clinical reasoning manifests when critical thinking is applied in identifying the appropriate interventions in a given client situation, which is referred to as clinical judgment. Clinical reasoning is a cognitive process that utilizes thinking tactics to interpret client assessment data (clinical judgment). The focus is to formulate a plan of care to meet the identified needs collaboratively. Provision of safe patient care requires sound clinical decision making. Multiple studies have described the concept of clinical reasoning. Victor-Chmil [2], for instance, described the clinical judgment as a clinical situation analysis guided by critical thinking. The nurse analyses the client's status and utilizes her necessary thinking skills to determine the way forward in addressing the identified needs.

Benner, Leonard, Day, and Sutphen [3], on the other hand, states that the manifestation of a nurse thinker is in their clinical reasoning abilities. Nurse thinkers express their capabilities to pick cues from client assessment data and institute timely responses to those findings [3]. The nurse's responsibility is to detect the often-instant changes in client assessment data, implement nursing and collaborative actions, and evaluate therapy response.

Copyright (C) 2020 The Author(s): This is an open-access article distributed under the terms of the Creative Commons Attribution 4.0 International License (CC BY-NC 4.0) which permits unrestricted use, distribution, and reproduction in any medium for non-commercial use provided the original author and source are credited. 
Therefore, clinical education should have its core objective to develop nurse professionals who are critical thinkers in every patient situation [4]. There is a need for evidence-based novelty in clinical teaching for nursing students to develop clinical judgment skills and integrate theory into clinical practice. Whatever method is chosen for clinical education, the focus should be whether that strategy will help the student nurse integrates what they learned in the classroom to what they encounter in the clinical setting, as well as prepares them sufficiently to practice as professionals [5, 6]. According to Walker et al. [4], clinical nursing skills do not only involve performing tasks; it can identify patient needs, prioritize those needs, develop a plan to meet those needs, and evaluate the outcome of the intervention. These elements are characteristic of sound clinical judgment.

The current demand for inclusion of emerging issues like changing disease patterns, technology, and knowledge explosion into the curriculum has expanded the amount of content to be covered for the undergraduate nursing program to prepare the students to function in the ever-dynamic health care arena. These changes have affected the duration of time the student nurses spend in the clinical environment so that there is no enough time to learn required clinical skills [7]. Practical strategies for student learning and teaching need to be explored to improve student learning. Nursing students in training need exposure to real-life experience to assimilate theoretical knowledge acquired in the classroom with that which occurs in the clinical environment. The need for nursing students to become clinically competent while in their training has been supported by many studies that have linked poor quality health care to nurses' knowledge and skills, including clinical judgment $[8,9]$. Despite this recognition by the Nursing Council of Kenya, evidence locally is highly suggestive in reporting that new graduates are still not capable of sound clinical judgments [10].

A cascade of gaps has been cited between nursing policy, training, competency, and practice in Kenya, with studies showing that of the graduates, not all possess good clinical judgment skills. Findings indicated a need to examine each step along the nurse capacity-building cascade, from policy to training, training to competency, and competency to practice, to identify barriers and opportunities to bridge the gaps in health delivery [10-12].

In the light of the gaps in clinical judgment skills exhibited among graduates, a shift to integrated clinical teaching methods has been proposed by several studies [13-16]. Therefore, it has become necessary to develop appropriate teaching-learning strategies to enhance the undergraduate nursing student's higher-order thinking skills to execute sound clinical judgment. Therefore, this study evaluated the effect of combining clinical teaching tools on undergraduate nursing students' clinical judgment skills on clinical placement in Kenya to enhance clinical judgment skill development.

\section{ReSEARCh Methodology \\ Research design and setting}

A quasi-experimental study design was adopted to identify the effect of combining clinical teaching tools: concept mapping and reflective journaling on undergraduate nursing students' clinical judgment competency scores. The study was carried out in Kenya between February to August 2018 in a National Teaching and Referral Hospital.

\section{Target population}

The participants were second-year and third-year undergraduate nursing students from a public university on medical surgical nursing clinical practicum at a National Referral Hospital. Those reporting for their medical-surgical clinical experience at the time of data gathering were approached to participate in the study. Those who consented to participate in the study were $82(79 \%)$ of the targeted 104 participants. The consenting participants were grouped into their clusters based on the year of study. The groupings and ward allocation were conveniently done based on competencies required. The second years were in 8 groups of 8-9 students, while the third years were in 4groups of 8-9 students. Simple random cluster sampling was used to allocate each group into either an intervention or comparison group.

\section{Research Instrument}

Data on the clinical judgment competencies were collected using pre-test and post-test assessment tools. The tools had five domains examined: the ability to identify patient care needs, interpret findings, prioritizing, anticipating physician's orders, and evaluating the outcome of the intervention. The nursing process informed the domains and the five rights of the clinical reasoning cycle by Levett- Jones [17].

\section{Reliability and validity of the research instrument}

The scoring tool's internal consistency was ascertained by sharing the device with three experts from different universities teaching undergraduate nursing to evaluate the tool for both construct and face validity. Once the tool was adjusted to the two experts' suggestions, it was pilot tested with students on clinical placement at a Middle-level Hospital to ensure the case study was precise. The tool was again subjected to reliability evaluation by rating randomly selected student response sheets by three different faculty members from various universities at the pilot testing time. Simple 
interrater reliability was calculated to ascertain the appropriateness of the marking key and clarity of questions. The result revealed the interrater reliability of 0.73

\section{Ethical consideration}

The KNH-UoN Ethics and Research Committee granted ethical approval to conduct this study. The National Commission gave further permission for Science Technology and Innovation (NACOSTI). Each of the participants signed a consent form.

\section{Procedure for data collection}

The pre-test was administered in a classroom setting at the University before the clinical practicum commenced to the 82 consenting participants. The students were conveniently allocated to the wards in groups of 8-9, a total of 12 groups. The groups assigned to the control and intervention group were based on simple random sampling in clusters of $3^{\text {rd }}$ year and $2^{\text {nd }}$ year. The students in the intervention group developed one concept map per week. They did one reflective journal entry based on Gibb's reflective model, which was marked by a trained clinical preceptor and feedback given at the end of each week for 4-8 weeks. The students in the control group developed one nursing care-plan per week with weekly preceptor feedback.

\section{Methods of Data Analysis}

SPSS version 26 was used to analyse data. The pre-test and post-test scores were compared to identify clinical judgment skills development. For the primary outcome (change in the average clinical judgment skills mean score), a test for a difference in means for the intervention and control arms using a two-sided student t-test was undertaken. A secondary analysis was undertaken to explore which domains: identifying patient assessment data, interpreting the findings, coming up with an independent nursing intervention, anticipating physician orders, and evaluating the outcome of the intervention, followed the integrated clinical teaching approach.

\section{RESULTS}

Table 1 represents the demographic characteristics of the participants. The majority of the respondents who participated in this study were female (65.9\%). The mean age was 21years, with a standard deviation of 1.34 to 1.43 . Percentage of the $2^{\text {nd }}$ year versus $3^{\text {rd }}$ years was in the ratio of $1: 1.2$ as shown in table 1 below

Table-1: Participant Baseline Characteristics

\begin{tabular}{|c|l|l|}
\hline & Intervention group 41(\%) & Control group 41(\%) \\
\hline Age (yrs.) (mean, SD) & $\mathbf{( 2 1 . 5 0 , 1 . 3 4 )}$ & $\mathbf{( 2 1 . 5 9 , 1 . 4 3 )}$ \\
\hline Gender & & \\
male & $14(34.15)$ & $14(34.15)$ \\
Female & $27(65.85)$ & $27(65.85)$ \\
\hline Year of study & & \\
$2^{\text {nd }}$ Yr. & $19(46.34)$ & $25(60.98)$ \\
$3^{\text {rd }}$ Yr. & $22(53.66)$ & $16(39.02)$ \\
\hline
\end{tabular}

Source: Research Data (2020)

\section{Pre-test and post-test scores across cohort}

To evaluate the clinical judgment skills scores, the respondents were subjected to an individualized supervised pre-clinical and post-clinical placement assessment in a classroom setting. The examination was based on a clinical case study analysis examining five domains to identify important assessment data, interpret the data, design a prioritized care plan, anticipate physician's orders, and design an evaluation strategy. The scores were grouped as per the Nursing Council pass mark for nursing students. Findings showed that most of the respondents (67.1\%) scored less than $50 \%$ all domains inclusive at pre-test for both cohorts, but at post-test, there was improvement in the overall scores, with $63.8 \%$ scoring at expectation. Further analysis shows that the improvement in post-test scores was more apparent in the intervention cohort with some of the respondents $4.3 \%$ attaining an above expectation mark, which was not the case in the control group as shown in table 2 
Table-2: Pre-test and post-test scores across cohort

\begin{tabular}{|c|c|c|c|c|c|c|}
\hline & \multicolumn{3}{|l|}{ Pre-test } & \multicolumn{3}{|l|}{ Posttest } \\
\hline & \multicolumn{2}{|l|}{ Cohort } & \multirow[t]{2}{*}{ Total } & \multicolumn{2}{|l|}{ Cohort } & \multirow[t]{2}{*}{ Total } \\
\hline & Control & Intervention & & Control & Intervention & \\
\hline below expectation $<49 \%$ & $25(30.49 \%)$ & $30(36.59 \%)$ & $55(67.07 \%)$ & $13(18.84 \%)$ & $12(17.39 \%)$ & $25(36.23 \%)$ \\
\hline at expectation $50-79 \%$ & $16(19.51 \%)$ & $11(13.41 \%)$ & $27(32.93 \%)$ & $17(24.64 \%)$ & $24(34.78 \%)$ & $41(59.42 \%)$ \\
\hline above expectation $80-100 \%$ & 0 & 0 & 0 & 0 & $3(4.35 \%)$ & $3(4.35 \%)$ \\
\hline Total & $41(50 \%)$ & $41(50 \%)$ & $82(100 \%)$ & $30(43.48 \%)$ & $39(56.52 \%)$ & $69(100 \%)$ \\
\hline
\end{tabular}

Source: Research Data (2020)

Further analysis showed that most of those who scored below expectations at pre-test was second-year respondents compared to their third-year counterparts. Posttest results show that improvement in CJ scores was evident regardless of the year of study after the clinical teaching intervention (Table 3). However, being a third-year increase the odds of scoring higher after the clinical intervention.

Table-3: Pretest/post-test Scores across the year of study

\begin{tabular}{|c|c|c|c|c|c|c|}
\hline & \multicolumn{3}{|l|}{ Pre-test } & \multicolumn{3}{|l|}{ Posttest } \\
\hline & \multicolumn{2}{|l|}{ YEAR } & \multirow[t]{2}{*}{ Total } & \multicolumn{2}{|l|}{ YEAR } & \multirow[t]{2}{*}{ Total } \\
\hline & $\begin{array}{l}\text { 2nd Year } \\
\text { Students }\end{array}$ & $\begin{array}{l}\text { 3rd Year } \\
\text { Students }\end{array}$ & & $\begin{array}{l}\text { 2nd Year } \\
\text { Students }\end{array}$ & $\begin{array}{l}\text { 3rd Year } \\
\text { Students }\end{array}$ & \\
\hline $\begin{array}{l}\text { below expectation } \\
<49 \%\end{array}$ & $32(39.02 \%)$ & $23(28.05 \%)$ & $55(67.07 \%)$ & $20(28.99 \%)$ & $5(7.25 \%)$ & $25(36.23 \%)$ \\
\hline at expectation $50-79 \%$ & $12(14.63 \%)$ & $15(18.29 \%)$ & $27(32.93 \%)$ & $16(23.19 \%)$ & $25(36.23 \%)$ & $41(59.42 \%)$ \\
\hline \multirow{2}{*}{$\begin{array}{l}\text { above expectation } 80- \\
100 \%\end{array}$} & 0 & 0 & 0 & $2(2.90 \%)$ & $1(1.45 \%)$ & $3(4.35 \%)$ \\
\hline & $44(53.66 \%)$ & $38(46.34 \%)$ & $82(100 \%)$ & $38(55.07 \%)$ & $31(44.93 \%)$ & $69(100 \%)$ \\
\hline
\end{tabular}

Source: Research Data (2020)

\section{Performance by Domain at Pre-Test across Cohort}

The participants did a case study based pre-clinical test to evaluate their level of clinical judgment skills before exposure to the intervention. The domains assessed included the respondents' ability to identify significant patient data, interpret the findings, come up with prioritized nursing interventions, anticipate the possible physician orders based on the information provided, and evaluate response to therapy. The mean score ranged between $30-57 \%$ for all five domains regardless of the cohort that the respondents were in.

Table-4: Performance by Domain across Cohort at Pre-Test

\begin{tabular}{|l|l|l|l|l|l|l|}
\hline \multicolumn{2}{|l|}{ Cohort } & $\begin{array}{l}\text { Identification of } \\
\text { patient care } \\
\text { needs }\end{array}$ & $\begin{array}{l}\text { Interpreting } \\
\text { findings }\end{array}$ & Prioritizing & $\begin{array}{l}\text { Anticipating } \\
\text { orders }\end{array}$ & $\begin{array}{l}\text { Evaluating } \\
\text { outcomes of } \\
\text { intervention }\end{array}$ \\
\hline \multirow{3}{*}{ Control } & Mean & 51.839 & 57.056 & 35.771 & 30.317 & 54.478 \\
\cline { 2 - 7 } & $\mathrm{N}$ & 41 & 41 & 41 & 41 & 41 \\
\cline { 2 - 7 } & $\begin{array}{l}\text { Std. } \\
\text { Deviation }\end{array}$ & 32.2408 & 18.3030 & 14.6670 & 22.2842 & 29.5936 \\
\hline \multirow{5}{*}{ Intervention } & Mean & 41.929 & 55.151 & 33.256 & 29.527 & 44.310 \\
\cline { 2 - 7 } & $\mathrm{N}$ & 41 & 41 & 41 & 41 & 31 \\
\cline { 2 - 7 } & $\begin{array}{l}\text { Std. } \\
\text { Tetal }\end{array}$ & 28.6181 & 17.0566 & 19.7345 & 20.4280 & 30.1930 \\
& $\begin{array}{l}\text { Overall } \\
\text { Mean }\end{array}$ & 46.884 & 56.104 & 34.513 & 29.922 & 49.394 \\
\cline { 2 - 7 } & $\mathrm{N}$ & 82 & 82 & 82 & 82 & 82 \\
\cline { 2 - 7 } & $\begin{array}{l}\text { Std. } \\
\text { Deviation }\end{array}$ & 30.7020 & 17.6073 & 17.3250 & 21.2476 & 30.1469 \\
\hline
\end{tabular}

Source: Research Data (2020)

\section{Performance by Domain across Cohort at Post-Test}

There was an evident improvement in the mean score for both the intervention and control groups at the posttest. The integrated model group means score improved more in three domains: prioritizing, anticipating orders, and evaluating higher-order clinical judgment domains while the traditional model means score for the domain of assessment and interpreting findings was higher comparatively. The finding shows that the integrated model is more likely to 
Wachira Serah et al., South Asian Res J Nurs Health Care; Vol-2, Iss-6 (Nov-Dec, 2020): 117-123

improve the higher-order clinical judgment scores than the traditional model. However, the use of NCP still has a role in helping students develop the skill of making sense of the data obtained through patient assessment (Table 4.6)

Table-5: Performance by Domain across Cohort at Post-Test

\begin{tabular}{|l|l|l|l|l|l|l|}
\hline \multicolumn{2}{|c|}{ Cohort } & $\begin{array}{l}\text { Identificatio } \\
\text { n of patient } \\
\text { care needs }\end{array}$ & $\begin{array}{l}\text { Interpreting } \\
\text { findings }\end{array}$ & $\begin{array}{l}\text { Prioritizi } \\
\text { ng }\end{array}$ & $\begin{array}{l}\text { Anticipating } \\
\text { orders }\end{array}$ & $\begin{array}{l}\text { Evaluating the } \\
\text { outcomes of the } \\
\text { intervention }\end{array}$ \\
\hline \multirow{3}{*}{ Control } & Mean & 66.437 & 65.000 & 40.500 & 37.333 & 45.557 \\
\cline { 2 - 7 } & $\mathrm{N}$ & 30 & 30 & 30 & 30 & 30 \\
\cline { 2 - 7 } & $\begin{array}{l}\text { Std. } \\
\text { Deviation }\end{array}$ & 23.1443 & 13.2613 & 23.9378 & 18.9251 & 21.4333 \\
\hline \multirow{5}{*}{ Intervention } & Mean & 63.369 & 61.667 & 50.256 & 46.923 & 53.423 \\
\cline { 2 - 7 } & N & 39 & 39 & 39 & 39 & 39 \\
\cline { 2 - 7 } & $\begin{array}{l}\text { Std. } \\
\text { Teviation }\end{array}$ & 25.5522 & 13.7330 & 19.2610 & 20.0531 & 23.9412 \\
\hline & $\begin{array}{l}\text { Overall } \\
\text { Mean }\end{array}$ & 64.703 & 63.116 & 46.014 & 42.754 & 50.003 \\
\cline { 2 - 7 } & N & 69 & 69 & 69 & 69 & 69 \\
\cline { 2 - 7 } & $\begin{array}{l}\text { Std. } \\
\text { Deviation }\end{array}$ & 24.4060 & 13.5338 & 21.8043 & 20.0099 & 23.0576 \\
\hline
\end{tabular}

Source: Research Data (2020)

Relationship between change in scores across Gender, Cohort, and Cluster

A Chi-square test of independence was done to evaluate whether gender, year of study, and cohort influenced the test scores. The change in score was set at least a 5\% improvement and above. The finding shows that being male or female and being a second-year or a third-year is not likely to improve the CJ score. However, being in the integrated clinical teaching cohort is more likely to improve the scores regardless of gender and year of study $(p=0.035 ; 95 \% \mathrm{CI})$.

Table-6: Relationship between improvement of CJ Skills Scores across Gender, Cluster, and Cohort

\begin{tabular}{|c|c|c|c|c|c|}
\hline \multirow{3}{*}{\multicolumn{2}{|c|}{ General Characteristics }} & Improvement in CJ & Improvement in CJ & Total & \multirow[t]{3}{*}{$\mathbf{P}$} \\
\hline & & & & & \\
\hline & & $\mathbf{N}(\%)$ & $\mathbf{N}(\%)$ & $\mathbf{N}(\%)$ & \\
\hline \multirow[t]{3}{*}{ Cohort } & Intervention & $16(41)$ & $23(59)$ & $39(56.5)$ & $0.035 *$ \\
\hline & Control & $20(66.7)$ & $10(33.3)$ & $30(43.5)$ & \\
\hline & Total & $36(52.2)$ & $33(47.8)$ & $69(100)$ & \\
\hline \multirow[t]{3}{*}{ Gender } & Male & $11(47.8)$ & $12(52.2)$ & $23(33.3)$ & 0.609 \\
\hline & Female & $25(54.3)$ & $21(45.7)$ & $46(66.7)$ & \\
\hline & Total & $36(52.2)$ & $33(47.8)$ & $69(100)$ & \\
\hline \multirow[t]{3}{*}{ Year } & 2nd Year students & $20(52.6)$ & $18(47.4)$ & $38(55.1)$ & 0.933 \\
\hline & 3rd Year students & $16(51.6)$ & $15(48.4)$ & $31(44.9)$ & \\
\hline & Total & $36(52.2)$ & $33(47.8)$ & $69(100)$ & \\
\hline
\end{tabular}

Source: Research Data (2020)

\section{Relationship between pre-test and post-test score results across cohort}

The mean of the pre-test and post-test scores were compared using a student t-test to identify which of the two clinical teaching models (Traditional or integrated) had a more significant effect on the CJ skills scores of the undergraduate student nurses. The findings (Table showed that the application of the integrated model in clinical teaching is more likely to result in improvement of $\mathrm{CJ}$ skills scores in undergraduate nurse training compared to the use of NCP alone $(\mathrm{P}<0.05 ; 95 \% \mathrm{CI})$ 
Table-7: Paired T-Test for Post-test and Pre-tests

\begin{tabular}{|c|c|c|c|c|c|c|c|c|c|}
\hline & \multicolumn{5}{|c|}{ Paired Differences } & \multirow[t]{3}{*}{$\mathbf{t}$} & \multirow[t]{3}{*}{ df } & \multirow{3}{*}{$\begin{array}{l}\text { Sig. (2- } \\
\text { tailed) }\end{array}$} \\
\hline & & \multirow[t]{2}{*}{ Mean } & \multirow[t]{2}{*}{$\begin{array}{l}\text { Std. } \\
\text { Deviation }\end{array}$} & \multirow{2}{*}{$\begin{array}{l}\text { Std. } \\
\text { Error } \\
\text { Mean }\end{array}$} & \multicolumn{2}{|c|}{$\begin{array}{l}95 \% \text { Confidence Interval } \\
\text { of the Difference }\end{array}$} & & & \\
\hline & & & & & Lower & Upper & & & \\
\hline $\begin{array}{l}\text { Pair } \\
1\end{array}$ & $\begin{array}{l}\text { Control Posttest } \\
\text { - Control Pretest }\end{array}$ & 2.9466 & 15.17402 & 2.77038 & -2.71941 & 8.61274 & 1.064 & 29 & .296 \\
\hline $\begin{array}{l}\text { Pair } \\
2\end{array}$ & $\begin{array}{l}\text { Intervention } \\
\text { posttest } \\
\text { Intervention } \\
\text { Pretest }\end{array}$ & 14.100 & 14.39815 & 2.30555 & 9.43266 & 18.76734 & 6.116 & 38 & .000 \\
\hline
\end{tabular}

\section{DISCUSSION}

Most of the respondents in this study had a mean age of 21.55. This age compares well with university students' expected age in the second and third years in Kenya. The majority of students will enter university education at age 19, having completed 12years of primary and secondary education.

Combining concept mapping and reflective journaling was more likely to improve clinical judgment skills scores than the nursing process alone. This finding agrees with multiple studies that have found that students' performance level in critical thinking and clinical judgment skills is improved by the application of integrated models $[16,15,18]$. However, most of these studies were done wholly or partially in a simulation laboratory context rather than an actual clinical site. This study's findings support the use of combined clinical teaching tools that are student-led to improve clinical judgment scores even when a resource-constrained unpredictable environment characterizes the clinical site.

The finding that the students had difficulty identifying patient care needs at the pre-test aligns with the results of a study done by Lasater and Nielson [19], which revealed that students had trouble noticing salient client data. Thus this finding is not only limited to resource-constrained environments. Alfayoumi [16] also documented similar student findings having difficulty identifying the significant patient history and assessment findings. There is, therefore, a need to identify strategies to close the gap during theoretical instruction.

This study's intervention improved the students' ability to identify patient care needs and interpret their findings. These findings differ with Alfayoumi [16], who found out that combining clinical teaching tools improved all clinical judgment domains except the domain of engagement, which involves the extent to which a student identifies something as a problem in a client. However, the conclusion that students can interpret patient assessment findings better when utilizing concept maps and reflective writing in combination confirms Alfayoumi's findings; integrating multiple clinical teaching tools improves the background information of normal and abnormal results among student nurses [20].

\section{Implications for clinical education}

There is a need to embrace the evidence-based practice in clinical teaching to enhance clinical judgment development. There is overwhelming evidence that no single clinical teaching tool is adequate in enhancing CJ skills. Integrating tools will go a long way in helping student nurses become competent practitioners.

\section{Limitations of the study}

This study's main limitation is that the data collection was carried out in a resource-constrained environment where consistent student supervision may be a challenging affair. The other limit is that the data collection process was interrupted due to a national crisis necessitating University closure and sudden withdrawal of participants from the clinical site led to participant fatigue because the intervention period was extended.

\section{RECOMMENDATIONS}

The current study guides in formulating recommendations. Firstly, the study suggests combining clinical teaching tools to be embraced and embedded in the National undergraduate nursing curricula by the Nursing Council of Kenya and tertiary institutions. This will enhance content absorption and the integration of skills by undergraduate students. Secondly, similar research is carried out in multiple clinical sites to enhance the evidence's strength. Finally, Evaluation of faculty perception on the use of the various tools should be encouraged as it may encourage uptake of integrated clinical teaching methodologies 


\section{CONCLUSION}

Combining concept mapping and reflective journaling improves the clinical judgment skills of undergraduate nursing students. Improvement is more pronounced in identifying patient care needs and interpreting findings that are the basis for further interventions in most client situations.

\section{REFERENCE}

1. Simmons, B. (2010). Clinical reasoning: concept analysis. Journal of Advanced Nursing 66(5), 1151-1158.

2. Victor-Chmil, J. (2013). Critical thinking versus clinical reasoning versus clinical judgment. Nurse Educator: $38(1)$ 34-36

3. Benner, P., Sutphen, M., Leonard, V., \& Day, L. (2010). Educating nurses: A call for radical transformation. San Francisco, CA: Jossey-Bass.

4. Walker, S., Dwyer, T., Broadbent, M., Moxham, L., Sander, T., and Edwards, K. (2014). Constructing a nursing identity within the clinical environment: The student nurse experience. Contemporary Nurse: A Journal for the Australian Nursing Profession, 49(12):103-112.

5. Fitzgerald, C., Rodger, S., Davila, W., Millar, F., \& Allison, H. (2011). What makes a quality occupational therapy practice placement? Students' and practice educators' perspectives. Australian Occupational Therapy Journal, 58(3): 195-202

6. Newberry, J. (2007). Indicators of practice education quality in health care organizations: a literature review. Vancouver: BC Practice Education Initiative http://www.hspcanada.net/docs/quality_indicators/quality_indicators.pdf_Nursing Education Perspectives.26, 5,272-277.

7. Chojecki, P., Lamarre, J., Buck, M., St-Sauveur, I., Eldaoud, N., \& Purden, M. (2010). Perceptions of a peer learning approach to pediatric clinical education. International Journal of Nursing Education Scholarship, 7(1).

8. Mutisya, A. K. (2008). Factors affecting clinical decision making by nurses at the critical care unit in Kenyatta National Hospital (Doctoral dissertation, University of Nairobi).

9. Osotsi, B. F., Mutema, A., Kangethe, S., \& Orodho, J. A. (2014). Trainees' and Trainers' Perspectives on Effectiveness of Clinical Training for Nursing Students in Kenya. Journal of Emerging Trends in Educational Research and Policy Studies, 5(3), 335.

10. Wachira, S., Mageto, I., \& Mapesa, J. (January, 2017). The self-assessed clinical judgment competencies of newly graduated nurses post internship in Kenya. International Journal of Nursing Education Volume 9 Number 1 DOI: 10.5958/0974-9357.2017.00023.X; ISSN: 0974-9349

11. Smith, J., Odera, D. N., Chege, D., Muigai, E. N., Patnaik, P., Michaels-Strasser, S., \& Dohrn, J. (2016). Identifying the gaps: An assessment of nurses' training, competency, and practice in HIV care and treatment in Kenya. Journal of the Association of Nurses in AIDS Care, 27(3), 322-330.

12. Luciana, N. Syombua, M., \& Omondi E (2016) Gaps in Clinical Instruction: Student Nurses' Perceptions. Kenyan Journal of Nursing \& Midwifery, 1:1, 20-28

13. LaMartina, K., \& Ward-Smith, P. (2014). Developing critical thinking skills in undergraduate nursing students: The potential for strategic management simulations. Journal of Nursing Education and Practice, 4(9), 155.

14. Curl, E. D., Smith, S., Chisholm, L. A., McGee, L. A., \& Das, K. (2016). Effectiveness of integrated simulation and clinical experiences compared to traditional clinical experiences for nursing students. Nursing Education Perspectives, 37(2), 72-77.

15. Hansen, J., \& Bratt, M. (2017). Effect of sequence of simulated and clinical practicum learning experiences on clinical competency of nursing students. Nurse educator, 42(5), 231-235.

16. Alfayoumi, I. H. (2019). Blending teaching strategies to improve nursing students' clinical judgment abilities cns.sciedupress.com Clinical Nursing Studies, 7(2) DOI: 10.5430/cns.v7n2p54 URL: https://doi.org/10.5430/cns.v7n2p54

17. Levett-Jones, T., Hoffman, K. Dempsey, Y. Jeong, S., Noble, D., Norton, C., Roche, J., \& Hickey, N. (2010). The 'five rights' of clinical reasoning: an educational model to enhance nursing students' ability to identify and manage clinically 'at risk' patients. Nurse Education Today, 30(6), 515-520.

18. Zarifsanaiey, N., Amini M., \& Saadat, F. (2016). A comparison of educational strategies for the acquisition of nursing student's performance and critical thinking: simulation-based training vs. integrated training (simulation and critical thinking strategies).BMC Med Educ.; 16(1):294.

19. Lasater, K., \& Nielsen, A. (2009). The influence of concept-based learning activities on students' clinical judgment development. Journal of Nursing Education, 48(8), 441-446.

20. Nursing Council of Kenya. (2012). Policy guidelines for BSN training in Kenya 